Seungjin Han*

\title{
Sellers' Implicit Collusion in Directed Search Markets
}

DOI 10.1515/bejte-2015-0106

Published online June 2, 2016

Abstract: This paper studies a competing-mechanism game for directed search markets in which multiple sellers simultaneously offer selling mechanisms to multiple buyers in order to compete for trading opportunities and profits. Buyers approach any particular seller via directed search, but there can be mis-coordination among buyers in the sense that they choose all the sellers offering the same mechanism with equal probability. A seller's mechanism can be sufficiently general to make his trading price contingent on participating buyers' messages, which may reflect changes in trading prices somewhere else. This allows sellers to sustain implicit collusion. This paper focuses on symmetric equilibria in which sellers offer the same mechanism that induces buyers' expost truth telling on market information. It provides the characterization of all symmetric ex-post truth telling equilibrium allocations and comparative statics regarding the range of equilibrium prices and profits. In a large market, the probability that sellers can sell their products at collusive prices depends on the ratio of buyers to sellers.

Keywords: implicit collusion, competing mechanism, online markets, clickstream, robust equilibrium

JEL Classification: C71, D82

\section{Introduction}

In on-line markets, many sellers adopt the technique called "click stream" for their price offers. This technique allows a seller's web site to record parts of the screen that a buyer clicks while she browses the web or uses software applications. Peters (2014) shows how sellers may utilize this technique to make their pricing depend on the buyers' clicking or web browsing behavior; for example, Amazon.com sells warranties along with electronic products such as computers. If you choose a computer that you want to buy, there is a little check box below

*Corresponding author: Seungjin Han, Department of Economics, 1280 Main Street West, McMaster University, Hamilton, Ontario, Canada L8S 4M4, E-mail: hansj@mcmaster.ca 
the "Add to Cart" button, which offers a warranty at some price. By checking the box, you can purchase the warranty at that price.

As Peters points out, a seller's web site or the computer program that operates it can, in fact, be thought of as a selling mechanism and a buyer's clicks as her binary messages. He argues that a buyer's clicking behavior for the warranty purchase may reflect her market information on other competing sellers' price offers because she is probably looking for better deals. Therefore, bypassing the price offer may have nothing to do with the buyer's utility from the warranty, but it may suggest that the buyer has seen a lower price offer somewhere else. ${ }^{1}$ As more buyers bypass the price offer by leaving the little box unchecked, the seller may subsequently lower its price. It means that even if sellers' web sites do not explicitly make their price offer contingent on other competing sellers' prices, they can do so based on buyers' clicking behavior. Therefore, sellers may charge prices higher than the competitive level even without explicit collusion. In that sense, on-line markets may provide sellers a platform where they can strategically design their selling mechanisms (i. e., web sites) for implicit collusion. Given the simplicity of the binary messages, collusive pricing through this type of mechanisms can be more prevalent when products are standardized and values of the products are more or less known in the market (e.g., warranty or a computer).

In the competing mechanism literature (Yamashita 2010; Peters and Troncoso-Valverde 2013), it is of great interest to analyze how competing sellers design their mechanisms that make their terms of trade responsive to buyers' messages which reflect changes in the market, e.g., changes in competing sellers' mechanisms, terms of trade, etc. ${ }^{2}$ Yamashita (2010) assumes that all buyers send messages to all sellers, given that they can trade with all sellers. Therefore, which seller to select is not modelled as part of the buyers' endogenous decision. He shows that, if there are at least three or more buyers in the market, it is very convenient, at least conceptually, to make buyers reveal their market information. ${ }^{3}$ Suppose that a seller offers a selling mechanism that makes his terms of trade only responsive to the same messages on market

1 As Peters mentions, a buyer may leave the little box unchecked because she does not value the warranty at all, but his point is that a buyer's clicking behavior may signal her market information.

2 If a buyer's payoff type is private information, she is usually asked to report her type and the market information that she has. Whether a buyer's payoff type is private information or not, a seller may want to ask buyers to report their market information (i. e., information on what competing sellers are doing such as their selling mechanisms, terms of trade, etc.)

3 If there is monetary transfer between a principal (e. g., seller) and an agent (e. g., buyer), the truthful revelation of market information is possible even with two agents. 
information sent by more than half of participating buyers. If a seller has multiple buyers, he can compare their messages on market information to see if they are consistent with one another. If all messages are the same except one, then the seller knows that the buyer who sends the inconsistent message lies when all the others tell the true market information.

Peters and Troncoso-Valverde (2013) extend Yamashita's approach to characterize a set of equilibrium allocations that can be supported in a competing mechanism game where traders compete in offering their trading mechanisms. They show that this set is very large. ${ }^{4}$ The fact that a competing mechanism game can support a large set of allocations in equilibrium is not because of traders' private information on their payoff type, but rather because of market information that is transmitted by multiple participants' truthful reporting.

In many cases, however, it is natural to think of the number of buyers participating in a particular seller's mechanism (or web site in any given time) as a stochastic realization, so that there may exist a positive probability that a seller may have only one participating buyer. If only one buyer chooses a seller's mechanism, it is not easy to tell whether this single buyer reports the true market information or not because there is no other message with which the seller can compare it. This may create a limit in the scope of implicit collusion among sellers.

This paper studies sellers' implicit collusion when a seller faces a stochastic realization of buyers participating in her selling mechanism. A competing mechanism game (Yamashita 2010; Peters and Troncoso-Valverde 2013) is applied to a simple directed search market where $m$ sellers produce homogenous products. A seller can produce each unit of the product at a constant marginal cost, which is normalized to zero for simplicity, and each unit of the product is not divisible. Each one of the $n$ buyers needs only one unit, so that she selects only one seller for purchasing the product after observing the selling mechanisms offered. The buyers' valuation of the product is public information and fixed to one. A seller has no capacity constraint and can serve all buyers who select him. Therefore, his production depends on the actual number of buyers who select him.

Buyers can approach any particular seller via directed search, but they do not discriminate among sellers who offer the same selling mechanisms. This makes them choose all the sellers offering the same mechanisms with equal probability. The buyer's non-discriminatory selection behavior reflects the lack

4 If a trader's payoff type is private information, any incentive compatible allocation (Myerson 1997) that a single mechanism designer can carry out with all sellers and buyers as participants can be supported as an equilibrium in a competing mechanism game. 
of coordination among buyers as to which sellers to select in a directed search market and it induces a probability distribution of the number of buyers selecting a particular seller even in a symmetric equilibrium where sellers who sell the homogenous products offer the same selling mechanisms. ${ }^{5}$

\subsection{Truthful Revelation of Market Information}

After observing the mechanisms that sellers simultaneously offered in the market, each buyer selects one seller, subject to her non-discriminatory selection behavior; that is, she will select any seller with equal probability if their mechanisms are the same. Each buyer sends a message to the seller she selects, without observing how many buyers select the same seller. The seller's mechanism then specifies his price as a function of messages sent by participating buyers.

A seller's mechanism should provide participating buyers with incentives to report the true market information. We consider ex-post truth telling in the sense that truth telling is ex-post optimal for a participating buyer based her (ex-post) payoff at each possible number of participating buyers given that those other participating buyers all report the truthful messages. ${ }^{6}$

Multiple buyers participate in a seller's mechanism, the seller can compare their messages on market information. This makes it possible for a seller to design a mechanism in which it is ex-post optimal for a participating buyer to report a truthful message, at the communication stage, on whether or not a competing seller has deviated given that the other participating buyers also report the truthful message. How can he do that if there is only one participating buyer? Since it is not possible to verify whether this single buyer reports the truthful message or not, the only way to ensure the property of ex-post truth telling is that the seller fixes his price regardless of the single participating buyer's message when there is only one participating buyer.

For a participating buyer's ex-post truth telling to a seller regardless of the number of buyers who select him, we consider a mechanism with the binary report (i. e., two possible messages) and the worst punishment (lowering the price down to zero when more than half of multiple participating buyers report a

5 See Peters $(1991,1997)$ for more discussion.

6 Truth telling is said to be interim optimal if it is optimal for a participating buyer based on her expected (interim) payoff when the other participating buyers report the truthful messages. When buyers employ mixed selection strategies in an equilibrium, a buyer's expected (interim) payoff upon reporting a message depends on the non-degenerate probability distribution of the number of the other participating buyers. Because the notion of ex-post truth telling is independent of buyers' selection strategies, it is more convenient to work with ex-post truth telling. 
competing seller's deviation). In this class of mechanisms, a participating buyer can send one of two messages, $\{0,1\} .^{7}$ If there is only one participating buyer, the seller's price is fixed and independent of the buyer's message. If more than half of multiple participating buyers send the same message, the mechanism interprets it as the true market information (strict majority rule). If the strict majority of participating buyers report a deviation by a competing seller, the mechanism lowers the seller's price down to zero. If the strict majority of $k$ participating buyers report no deviation by any other seller, then the seller charges the price $\hat{p}_{k}$ that he wants to charge in equilibrium. If there are two participating buyers and their messages are inconsistent, the seller raises his price to one. Given any number of participating buyers, no buyer has an incentive to report a message that is inconsistent with the messages sent by the other participating buyers when their messages reflect the true market information. Therefore, the mechanism ensures ex-post truth telling regardless of the number of buyers who participate in it. ${ }^{8}$

\subsection{Equilibrium Analysis}

Sellers do not have to offer mechanisms with the binary report and the worst punishment. Sellers may come up with any mechanism (if they think it is profitable) and hence we can generally consider a competing mechanism game where a seller offers a mechanism from an arbitrary set of mechanisms.

We first consider a (symmetric) equilibrium with prices responsive to only multiple buyers' messages, in a competing mechanism game with a certain set of mechanisms. In this equilibrium, the price can be responsive to only multiple buyers' messages, while being fixed only upon a single buyer's participation. Proposition 1 shows that any equilibrium allocation of a competing mechanism game with any arbitrary set of mechanisms can be reproduced by an ex-post truth telling equilibrium of an auxiliary competing mechanism game. In such a game a seller can either deviate to a single fixed price or stick to his equilibrium mechanism with the binary report and the worst punishment, and buyers truthfully report to non-deviating sellers whether or not a competing seller deviates at the communication stage.

7 Where 1 means deviation by some competing seller and 0 means no deviation.

8 If there are three or more participating buyers, any single buyer's deviation from the same truthful messages sent by the other buyers cannot change the seller's price. If there is only two buyers, any single buyer's deviation from the other buyer's truthful message will hike the price up to one, the highest level. 
Although the auxiliary competing mechanism games provide a way to capture every equilibrium with prices responsive to only multiple buyers' participation, it is not clear whether any ex-post truth telling equilibrium of such a game is robust to the possibility of a seller's deviation to any selling mechanism, let alone a single fixed price. Even when we focus on a truth-telling continuation equilibrium, where participating buyers truthfully report about a competing seller's deviation, there can be multiple truth-telling continuation equilibria upon a seller's deviation to an arbitrary mechanism, in terms of probabilities that buyers select sellers and their communication with a deviating seller.

An ex-post truth telling equilibrium in the auxiliary competing mechanism game is said to be robust if in every truth-telling continuation equilibrium no seller can gain from his deviation to any arbitrary mechanism. ${ }^{9}$ Theorem 1 provides the necessary and sufficient condition for the robustness of an expost truth telling equilibrium of the auxiliary competing mechanism game. It shows that such an equilibrium is robust if and only if a seller cannot gain in every truth-telling continuation equilibrium upon a deviation to a single fixed price.

There is no $a$ priori reason to think that every ex-post truth telling equilibrium of an auxiliary competing mechanism game satisfies the necessary and sufficient condition for the robustness derived in Theorem 1, because an equilibrium is subject to a particular truth-telling continuation equilibrium, in terms of probabilities that buyers select sellers. Proposition 2 shows that, despite multiple truth-telling continuation equilibria upon a seller's deviation to a single fixed price in an auxiliary competing mechanism game, the condition for the robustness derived in Theorem 1 is satisfied for any ex-post truth telling equilibrium of an auxiliary competing mechanism game. ${ }^{10}$

9 The early literature on competing auctions (e. g., McAfee 1993) pointed out that an equilibrium of a competing mechanism may not be robust if the game restricts the set of mechanisms available for sellers. We adopt the notion of the robustness in Epstein and Peters (1999). For an equilibrium where buyers' messages reflect changes in the market, the robustness is based on the truth-telling continuation equilibrium where buyers truthfully reveal their market information to non-deviators. More discussion on this is found in Section 6.

10 Let $\left(\hat{p}_{1}, \ldots \hat{p}_{n}\right)$ be the price vector supported in an ex-post equilibrium of an auxiliary competing mechanism game, where $\hat{p}_{k}$ is the price charged by a seller to a buyer when $k$ buyers select him, for all $k=1, \ldots, n$. Proposition 2 shows that a seller's maximum payoff upon deviation to a single fixed price in an auxiliary competing mechanism game is the same across all continuation equilibria and that it is equal to $n \hat{p}_{1}$, which is a seller's payoff if he could sell his product to all buyers in the market at the price $\hat{p}_{1}$. This makes it possible to show that the necessary and sufficient condition of the strong robustness is satisfied for any ex-post equilibrium in an auxiliary competing mechanism game. 
Propositions 1 and 2 allow us to characterize all possible allocations in an equilibrium with prices responsive to only multiple buyers' participation by using an ex-post truth telling equilibrium of an auxiliary competing mechanism game. This characterization is presented in Proposition 3 and Corollary 1. The Section 5 of this paper also provides comparative statics on the range of prices and profits supportable in an ex-post truth telling equilibrium.

In an ex-post truth-telling equilibrium, a seller can punish a deviating seller only when multiple buyers select him, but always charges the same price $\hat{p}_{1}$ if there is only one participating buyer. This paper shows that for any given number of buyers and sellers, the upper bound of $\hat{p}_{1}$ is tied to the ratio of buyers to seller $\left(b=\frac{n}{m}\right)$, while its lower bound is the competitive price. The equilibrium price $\hat{p}_{k}$ with $k \geq 2$, however, can be as high as the monopoly price.

As the number of buyers and sellers goes to infinity, holding its ratio constant, we can derive the following limit properties: (i) the upper bound of $\hat{p}_{1}$ converges to the competitive price, (ii) the probability that a seller has only one buyer converges to $b e^{-b}$, and (iii) the probability that a seller has two or more buyers converges to $1-(1+b) e^{-b}$. Therefore, even in a large market, sellers can charge collusive prices (i. e., prices higher than the competitive level) with probability $1-(1+b) e^{-b}$. This probability is increasing in $b$ but is strictly less than one for any given $b$.

\section{Preliminaries}

There are $m$ sellers and $n$ buyers with $m \geq 2$ and $n \geq 2$. Every seller can produce each unit of the homogenous non-divisible good at a constant marginal cost, which we normalize to zero for simplicity. There is no capacity constraint, so that a seller's production depends on the number of buyers who choose him. Each buyer has a unit demand for the good. There is no private information on the buyer's valuation in the sense that every buyer's valuation of the good is one. Sellers cannot charge negative prices because of limited liability, for instance. Since the buyer's valuation is one, the set of all possible prices is set to $[0,1]$.

Sellers can offer mechanisms to compete for trading opportunities and profits. Let $\mathcal{C}$ be the set of messages that each buyer can send upon participating in a mechanism. A seller's mechanism is denoted by $\gamma=\left\{\gamma_{k}\right\}_{k=1}^{n}$, where $\gamma_{k}: C^{k} \rightarrow[0,1]$ specifies the price charged by the seller when $k$ buyers participate in the seller's mechanism $\gamma$. For any $k, \gamma_{k}\left(c_{1}, \ldots, c_{k}\right)$ denotes the price when $\left(c_{1}, \ldots, c_{k}\right)$ is the array of messages sent by $k$ participating buyers. Buyers are symmetric in terms of their valuation of the good in our model. Therefore, we 
focus on anonymous selling mechanisms. This means that a mechanism does not depend on the identity of the buyer and hence, for each $k, \gamma_{k}$ is invariant with respect to the permutation of $\left(c_{1}, \ldots, c_{k}\right)$. Let $\Gamma$ be the set of all possible anonymous mechanisms that a competition model allows sellers to offer.

In a competing mechanism game with a set $\Gamma$, a seller can offer any mechanism in $\Gamma$. The timing of the game is as follows:

1. Each seller simultaneously offers a mechanism in $\Gamma$.

2. After observing the mechanisms offered by sellers, each buyer simultaneously chooses one seller subject to her non-discriminatory selection behavior.

3. Each buyer sends a message to the seller she selects, without observing the buyers who select the same seller.

4. Each seller charges the price that is determined by his mechanism given the messages that are sent by buyers who select him.

For a given set of mechanisms $\Gamma$, each buyer's strategic behavior is characterized by her selection strategy (i. e., which seller to select) and communication strategy (i. e., which message to send to the seller she selects). A buyer's communicated strategy is denoted by $c$. Suppose that a seller offers a mechanism $\gamma^{\prime}$ and the other sellers offer a profile of mechanisms $\gamma^{m-1}=(\gamma, \ldots, \gamma) \in \Gamma^{m-1}$. Then the buyer sends a message that is drawn from a probability distribution $c\left(\gamma^{\prime}, \gamma^{m-1}\right) \in \Delta(\mathcal{C})$ upon selecting the seller who offers $\gamma^{\prime}$.

Let $\pi$ denote a buyer's selection strategy. Suppose that one seller offers $\gamma^{\prime}$ and the other $m-1$ sellers offer $\gamma^{m-1}=(\gamma, \ldots, \gamma) \in \Gamma^{m-1}$. Then $\pi\left(\gamma^{\prime}, \gamma^{m-1}\right)$ denotes the probability with which the buyer selects the seller who offers $\gamma^{\prime}$. According to the terminology in Peters (1997), a buyer's selection strategy $\pi$ is incentive consistent if (a) every buyer employs $\pi$ (symmetry) and (b) two sellers are selected with equal probability if those two offer the same mechanism (nondiscrimination). The second condition for incentive consistency captures the lack of coordination among buyers. ${ }^{11}$ The incentive consistency implies that if

11 Mis-coordination among buyers is captured in a non-discriminatory selection behavior in a market where sellers offer the same mechanisms (e. g., Peters 1991, McAfee 1993, Burdett, Shi, and Wright 2001). In this case, a buyer's mixed selection strategy induces a non-degenerate probability distribution of buyers participating in a seller's mechanism. In contrast, buyers may coordinate perfectly so that the number of buyers participating in each seller's mechanism is exactly the same even if sellers offer the same mechanisms. In the literature on directed search markets, the latter is thought of as the one that requires a lot of coordination in a decentralized economy. Even when sellers offer different mechanisms, one can still consider a continuation equilibrium where buyers use mixed selection strategy (e. g., Peters 1997). 
a buyer selects the seller who offers $\gamma^{\prime}$ with probability $\pi\left(\gamma^{\prime}, \gamma^{m-1}\right)$, then she selects every other seller with equal probability $\left(1-\pi\left(\gamma^{\prime}, \gamma^{m-1}\right)\right) /(m-1)$, given $\gamma^{m-1}=(\gamma, \ldots, \gamma) \in \Gamma^{m-1}$. A strategy profile $\{c, \pi\}$ is called an incentive consistent continuation equilibrium in a competing mechanism game with $\Gamma$ if (i) it induces a Nash equilibrium of the normal form game defined by each possible profile of mechanisms in $\Gamma^{m}$ offered by sellers and (ii) every buyer's selection strategy $\pi$ is incentive consistent and every buyer chooses the same communication strategy $c$.

Given a communication strategy $c$ that every buyer chooses and any profile of the other sellers' mechanisms $\gamma^{m-1} \in \Gamma^{m-1}$, we can derive the price that a seller's mechanism $\gamma^{\prime}$ induces when there are $k$ participating buyers as follows.

$$
p_{k}^{\gamma^{\prime}}\left(\gamma^{m-1}, c\right)=\int_{c_{1} \in \mathcal{C}} \cdots \int_{c_{k} \in \mathcal{C}} \gamma_{k}^{\prime}\left(c_{1}, \ldots, c_{k}\right) d c\left(\gamma^{\prime}, \gamma^{m-1}\right) \times \cdots \times d c\left(\gamma^{\prime}, \gamma^{m-1}\right)
$$

Then the expected price that a buyer faces upon selecting a seller who offers $\gamma^{\prime}$ is

$$
\mathbb{E}\left[p_{k}^{\gamma^{\prime}}\left(\gamma^{m-1}, c\right)\right]=\sum_{k=1}^{n}\left(\begin{array}{l}
n-1 \\
k-1
\end{array}\right) \pi\left(\gamma^{\prime}, \gamma^{m-1}\right)^{k-1}\left(1-\pi\left(\gamma^{\prime}, \gamma^{m-1}\right)\right)^{n-k} p_{k}^{\gamma^{\prime}}\left(\gamma^{m-1}, c\right) .
$$

Subsequently, if a seller offers $\gamma^{\prime}$ given a profile of the other sellers' mechanisms $\gamma^{m-1} \in \Gamma^{m-1}$, the continuation equilibrium $\{c, \pi\}$ induces the seller's expected profit as

$$
\begin{aligned}
\Phi\left(\gamma^{\prime}, \gamma^{m-1}, c, \pi\right) & =\sum_{k=1}^{n}\left(\begin{array}{l}
n \\
k
\end{array}\right) \pi\left(\gamma^{\prime}, \gamma^{m-1}\right)^{k}\left(1-\pi\left(\gamma^{\prime}, \gamma^{m-1}\right)\right)^{n-k} k p_{k}^{\gamma^{\prime}}\left(\gamma^{m-1}, c\right) \\
& =n \pi\left(\gamma^{\prime}, \gamma^{m-1}\right) \mathbb{E}\left[p_{k}^{\gamma^{\prime}}\left(\gamma^{m-1}, c\right)\right] .
\end{aligned}
$$

We are interested in a symmetric equilibrium in which all sellers offer the same mechanism and a non-deviating seller's price may be responsive to multiple participating buyers' messages, but remains fixed upon only one buyer's participation, whether there is a deviating seller or not. This leads to the following definition of a symmetric equilibrium with prices responsive to only multiple buyers' messages.

Definition 1: $\{\gamma, c, \pi\}$ is a symmetric equilibrium with prices responsive to only multiple buyers' messages (hereafter equilibrium) in a competing mechanism game with a set of mechanisms $\Gamma$ if

1. $\{c, \pi\}$ is an incentive consistent continuation equilibrium and

2. for all $\gamma^{\prime} \in \Gamma, \Phi\left(\gamma, \gamma^{m-1}, c, \pi\right) \geq \Phi\left(\gamma^{\prime}, \gamma^{m-1}, c, \pi\right)$, and

3. for all $\gamma^{\prime}, \gamma^{\prime \prime} \in \Gamma, p_{1}^{\gamma}\left(\gamma^{\prime}, \gamma^{m-2}, c\right)=p_{1}^{\gamma}\left(\gamma^{\prime \prime}, \gamma^{m-2}, c\right)$. 
Conditions 1 and 2 above constitute the definition of an equilibrium of a competing mechanism game with $\Gamma$. Condition 3 is the additional condition for the equilibrium that shows that a non-deviating seller's price upon only one participating buyer is always the same, regardless of a deviating seller's mechanism.

\section{Binary Report and the Worst Punishment}

We would like to come up with a way to characterize the set of equilibrium allocations that can be supported in a competing mechanism game with an arbitrary set of mechanisms $\Gamma$. In a competing mechanism game, collusive outcomes are possible if buyers are able to report changes in the market such as a competing seller's deviation. The worst punishment that a seller can impose when he knows a competing seller is deviating is to lower his price down to zero. If a seller wants to implement this worst punishment, he only needs to know whether there is a deviating seller but not the details of a deviating seller's mechanism. Let $T=\{0,1\}$ be the set of binary messages, where " 0 " means no deviation and " 1 " means a deviation by at least one competing seller. ${ }^{12}$ Consider a mechanism $\varphi=\left\{\varphi_{k}\right\}_{k=1}^{n}$ with $\varphi_{k}: T^{k} \rightarrow[0,1]$ for each $k$, which specifies the seller's price as a function of $k$ participating buyers' messages. We define a class of mechanisms with the binary report and the worst punishment as follows.

Definition 2: Let $\left(p_{1}, \ldots, p_{n}\right)$ be a vector in $[0,1]^{n} \cdot \varphi=\left\{\varphi_{k}\right\}_{k=1}^{n}$ is a mechanism with the binary report and the worst punishment if $T=\{0,1\}$ and

1. $\varphi_{1}\left(t_{1}\right)=p_{1}$ for all $t_{1} \in\{0,1\}$

2. For any given $k \geq 2$ and any $\left(t_{1}, \ldots, t_{k}\right) \in T^{k}$,

$$
\varphi_{k}\left(t_{1}, \ldots, t_{k}\right)=\left\{\begin{array}{cl}
p_{k} & \text { if } \#\left\{\ell: t_{\ell}=0\right\}>\frac{k}{2} \\
0 & \text { if } \#\left\{\ell: t_{\ell}=1\right\}>\frac{k}{2}
\end{array}\right.
$$

3. If $k=2$ and $t_{1} \neq t_{2}$, then $\varphi_{k}\left(t_{1}, t_{2}\right)=1$.

4. For all other cases, the seller assigns some arbitrary price (e.g., the price of one).

12 Generally, a lot of coordination may be required for mechanism participants to interpret potentially abstract messages in an arbitrary mechanism in the same manner. However, a mechanism with binary messages may be tractable in terms of implementation because it only requires that a participating buyer send either one of the two messages. 
Property (i) shows that if there is only one participating buyer, a seller offers always the same price, say $p_{1}$, regardless of her message. Property (ii) shows that a seller offers price $p_{k}$ when the strict majority of multiple $k$ participating buyers report $t=0$ while lowering his price down to zero when the strictly majority report $t=1$. Property (iii) shows that if there are two participating buyers and their messages are inconsistent, a seller offers the highest price of one.

We can show that truth telling to a seller who offers a mechanism $\varphi$ with the binary report and the worst punishment is ex-post optimal for a participating buyer. It means that a buyer participating in $\varphi$ cannot increase her (ex-post) payoff at each possible number of participating buyers, by reporting an inconsistent message $t^{\prime} \neq t$ when the other participating buyers all report the truthful message $t$ on whether or not there exists at least one deviating seller. This makes a buyer's ex-post truth telling independent of the number of the other participating buyers.

We will show how to use the class of mechanisms with the binary report and the worst punishment in characterizing the set of equilibrium allocations in a competing mechanism game with a set of mechanisms $\Gamma$. For that, we start with Lemma 1 below. Suppose that $\left(p_{1}, \ldots, p_{n}\right) \in[0,1]^{n}$ is the vector of prices that is to be supported in an equilibrium.

Lemma 1: Let each seller be supposed to offer the corresponding mechanism $\hat{\varphi}$ with the binary report and the worst punishment, associated with the vector of prices $\left(p_{1}, \ldots, p_{n}\right) \in[0,1]^{n}$. Truth telling is ex-post optimal for a buyer upon participating in $\hat{\varphi}$.

Proof: Fix $\left(p_{1}, \ldots, p_{n}\right)$ to be a price vector for a seller who offers the corresponding mechanism $\hat{\varphi}=\left\{\hat{\varphi}_{k}\right\}_{k=1}^{n}$ with the binary report and the worst punishment defined in Definition 2. Suppose that $t \in T=\{0,1\}$ is the true state about whether or not there exists at least one seller who has deviated from $\hat{\varphi}$.

If a buyer is the only one buyer participating in a non-deviating seller's mechanism $\hat{\varphi}$, she will always be charged $p_{1}$ regardless of her message. Therefore, she can report the truthful message $t$.

Suppose there are two participating buyers $(k=2)$. Consider a buyer's reporting decision given that the other participating buyer reports the true message $t$. If the buyer sends a message $t^{\prime}$ that is inconsistent with $t$, the price becomes one according to property (iii). If the buyer sends the same message $t$ as the other participating buyer's message, then the price is either $p_{k}$ or 0 according to property (ii), depending on whether $t$ is 0 or 1 . Because $p_{k}$ is no more than one, the price that the buyer has to pay upon deviating to $t^{\prime}$ is always no less 
than the price she can pay upon sending the same message that the other buyer sends. Therefore, it is optimal for the buyer to send the same message $t$ as the one the other buyer sends.

Suppose there are three or more participating buyers $(k \geq 3)$. Consider a buyer's reporting decision given that all the other participating buyers send the true message $t$. Then, even if the buyer sends a message $t^{\prime}$ that is different from $t$, it does not change the price that the seller charges. Because the number of participating buyers who send the same message $t$ is $k-1$, it is still strictly greater than $k / 2$. Therefore, it is optimal for the buyer to send the same message $t$ as the one all the other buyers send.

To characterize every equilibrium of a competing mechanism with $\Gamma$, consider an auxiliary competing mechanism game where each seller can either offer a mechanism $\hat{\varphi}=\left\{\hat{\varphi}_{k}\right\}_{k=1}^{n}$ with the binary report and the worst punishment or deviate to a single fixed price. In this game, if a seller chooses a single fixed price, he always sells his product to every buyer at the price $p$.

Because of Lemma 1, we fix truth telling to any non-deviating sellers who offer $\hat{\varphi}$ without reference to the distribution of the number of participating buyers. ${ }^{13}$ Therefore, we only need to formulate a buyer's selection strategy. Let $\hat{\pi}\left(p, \hat{\varphi}^{m-1}\right)$ denote the probability with which a buyer selects the deviating seller who offers a fixed price $p \in[0,1]$ in an incentive consistent continuation equilibrium. Similar to eq. [2], we can derive a seller's expected payoff upon deviating to $p$ as $\Phi\left(p, \hat{\varphi}^{m-1}, \hat{\pi}\right)=n \hat{\pi}\left(p, \hat{\varphi}^{m-1}\right) p$. Let $\hat{\pi}\left(\hat{\varphi}^{m}\right)=1 / m$ denote the probability with which a buyer selects each seller in incentive consistent continuation equilibrium when no seller deviates. Then, each seller's expected profit is $\Phi\left(\hat{\varphi}, \hat{\varphi}^{m-1}, \hat{\pi}\right)=n \hat{\pi}\left(\hat{\varphi}^{m}\right) \mathbb{E}\left[\hat{\varphi}_{k}\left(0^{k}\right)\right]$, where

$$
\mathbb{E}\left[\hat{\varphi}_{k}\left(0^{k}\right)\right]=\sum_{k=1}^{n}\left(\begin{array}{c}
n-1 \\
k-1
\end{array}\right) \hat{\pi}\left(\hat{\varphi}^{m}\right)^{k-1}\left(1-\hat{\pi}\left(\hat{\varphi}^{m}\right)\right)^{n-k} \hat{\varphi}_{k}\left(0^{k}\right)
$$

is the expected price upon selecting a seller in an equilibrium.

Definition 3: $\{\hat{\varphi}, \hat{\pi}\}$ is an ex-post truth telling equilibrium (hereafter equilibrium) of an auxiliary competing mechanism game, where each seller can either offer the mechanism $\hat{\varphi}$ with the binary report and the worst punishment or deviate to a

13 Lemma 1 can be applied whether a seller deviates to a single fixed price or an arbitrary mechanism in $\Gamma$. The robustness of an equilibrium of an auxiliary competing mechanism game concerns the possibility of a seller's deviation to an arbitrary mechanism. We also use Lemma 1, when dealing with the robustness of the equilibrium in Theorem 1 in the next section. See the proof of Theorem 1 in Appendix. 
single fixed price, if (i) $\hat{\pi}$ constitutes an incentive consistent truth telling continuation equilibrium in which participating buyers submit truthful reports to nondeviating sellers and (ii) for all $p \in[0,1], \Phi\left(\hat{\varphi}, \hat{\varphi}^{m-1}, \hat{\pi}\right) \geq \Phi\left(p, \hat{\varphi}^{m-1}, \hat{\pi}\right)$.

Proposition 1 shows that for an equilibrium of a competing mechanism game with $\Gamma$, there exists an equilibrium of an auxiliary competing mechanism game in which equilibrium payoffs for buyers and sellers are all preserved.

Proposition 1: For an equilibrium $\{\gamma, c, \pi\}$ of a competing mechanism game with $\Gamma$, there exists an equilibrium $\{\hat{\varphi}, \hat{\pi}\}$ of an auxiliary competing mechanism game such that $\{\hat{\varphi}, \hat{\pi}\}$ preserves equilibrium payoffs for buyers and sellers;

$$
\begin{aligned}
& 1-\mathbb{E}\left[\hat{\varphi}_{k}\left(0^{k}\right)\right]=1-\mathbb{E}\left[p_{k}^{\gamma}\left(\gamma^{m-1}, c\right)\right], \\
& \Phi\left(\hat{\varphi}, \hat{\varphi}^{m-1}, \hat{\pi}\right)=\Phi\left(\gamma, \gamma^{m-1}, c, \pi\right) .
\end{aligned}
$$

Proof: See Appendix.

We can show the intuition behind Proposition 1. First, fix an equilibrium $\{\gamma, c, \pi\}$ of a competing mechanism game with $\Gamma$. Consider the corresponding mechanism $\hat{\varphi}=\left\{\hat{\varphi}_{k}\right\}_{k=1}^{n}$ with the binary report and the worst punishment that implements $\left[p_{1}^{\gamma}\left(\gamma^{m-1}, c\right), \ldots, p_{n}^{\gamma}\left(\gamma^{m-1}, c\right)\right]$ as the price vector that the seller charges when no seller deviates; that is, we can construct the mechanism satisfying conditions (i)-(iv) with

$$
\left[p_{1}, \ldots, p_{n}\right]=\left[p_{1}^{\gamma}\left(\gamma^{m-1}, c\right), \ldots, p_{n}^{\gamma}\left(\gamma^{m-1}, c\right)\right] .
$$

Therefore, the seller charges $p_{k}^{y}\left(\gamma^{m-1}, c\right)$ directly to $k$ participating buyers if no seller deviates and those $k$ participating buyers truthfully report $t=0$.

If no seller deviates from $\hat{\varphi}$, each buyer truthfully reports $t=0$ upon selecting each seller with probability $\hat{\pi}\left(\hat{\varphi}^{m}\right)=\tilde{\pi}\left(\gamma^{m}\right)=1 / m$. The expected price $\mathbb{E}\left[\hat{\varphi}_{k}\left(0^{k}\right)\right]=\mathbb{E}\left[p_{k}^{\gamma}\left(\gamma^{m-1}, c\right)\right]$ will be preserved. One possible type of mechanism in $\Gamma$ would be a constant mechanism that assigns the same price regardless of participating buyers' reports. Constant mechanisms are essentially equivalent to fixed prices. If $\{\gamma, c, \pi\}$ is an equilibrium of a competing mechanism game with $\Gamma$, it is clearly the case that a seller cannot gain by deviating to a constant mechanism (i. e., single fixed price). When every non-deviating seller offers the mechanism $\hat{\varphi}=\left\{\hat{\varphi}_{k}\right\}_{k=1}^{n}$ instead of $\gamma$, a buyer will select the deviating seller with a lower probability upon his deviation to a single fixed price $p$ than the probability with which she does when the same seller deviates to the corresponding constant mechanism, while every non-deviating seller offers $\gamma$. This is because the mechanism with the binary report and the worst punishment charges the lowest possible price (i. e., zero) upon multiple buyers' consistent reports $t=1$. 
Therefore, if a deviation to any constant mechanism is not profitable for a seller in an equilibrium $\{\gamma, c, \pi\}$ of a competing mechanism game with $\Gamma$, then it is not profitable to deviate to any single fixed price in the auxiliary competing mechanism game. This is how we proved Proposition 1.

\section{Robustness}

Proposition 1 shows that any equilibrium allocation of a competing mechanism game with $\Gamma$ can be reproduced by an equilibrium $\{\hat{\varphi}, \hat{\pi}\}$ of an auxiliary competing mechanism game. However, it is a different question whether any equilibrium $\{\hat{\varphi}, \hat{\pi}\}$ of an auxiliary competing mechanism game is robust to the possibility that a seller may deviate to a mechanism in $\Gamma$ instead of deviating to a single fixed price.

The literature on competing mechanism design (Epstein and Peters 1999; Peters and Troncoso-Valverde 2013; Yamashita 2010) is interested in the equilibrium allocations that can be supported when market information is truthfully revealed to non-deviating sellers on the path and also off the path following a competing seller's deviation. Therefore, the robustness analysis is based on a truth-telling continuation equilibrium where buyers report true market information (and also true payoff types if types are buyers' own private information) to non-deviating sellers. Even when we focus on an incentive consistent truthtelling continuation equilibrium, we may have multiple continuation equilibria in terms of the probabilities with which buyers select sellers and their communication with a deviating seller.

For the robustness analysis, we adopt the notion of a robust equilibrium studied in Epstein and Peters (1999). An equilibrium $\{\hat{\varphi}, \hat{\pi}\}$ of an auxiliary competing mechanism game is said to be robust to a set of mechanisms $\Gamma$ if no seller can gain in every incentive consistent truth-telling continuation equilibrium upon his deviation to any mechanism in $\Gamma$. This is stronger than the notion of weak robustness (Peters 2001): weak robustness of an equilibrium to $\Gamma$ only requires the existence of a truth telling continuation equilibrium where no seller can gain upon his deviation to any mechanism in $\Gamma .^{14}$

Theorem 1 provides the necessary and sufficient condition for the robustness of an equilibrium $\{\hat{\varphi}, \hat{\pi}\}$ of an auxiliary competing mechanism game.

14 See Peters (2001) for more discussion on weakly robustness and strongly robustness. Yamashita (2010) and Peters and Troncoso-Valerde (2013) adopt the notion of weak robustness. 
Theorem 1: Let $\{\hat{\varphi}, \hat{\pi}\}$ be an equilibrium of an auxiliary competing mechanism game. It is robust to any $\Gamma$ if and only if, for every incentive consistent truth-telling continuation equilibrium $\hat{\pi}^{\prime}$,

$$
\sup _{p \in[0,1]} \Phi\left(p, \hat{\varphi}^{m-1}, \hat{\pi}\right) \geq \sup _{p \in[0,1]} \Phi\left(p, \hat{\varphi}^{m-1}, \hat{\pi}^{\prime}\right)
$$

Proof: See Appendix.

As shown in the proof in the Appendix, a seller's deviation to a mechanism $\gamma^{\prime}$ in $\Gamma$ induces an expected price $p^{\prime}$ for a buyer upon selecting the deviating seller in a continuation equilibrium. Even if we focus on an incentive consistent truth telling continuation equilibrium to highlight the buyer's non-discriminatory selection behavior, there may be multiple incentive consistent truth telling continuation equilibria upon a seller's deviation to a mechanism in $\Gamma$, where a buyer uses an incentive consistent selection strategy, which is different from the one that he uses upon the same seller's deviation to the single fixed price $p^{\prime}$. Such a different incentive consistent truth telling continuation equilibrium may induce a higher expected profit to the deviating seller. This is why a seller may want to deviate to a mechanism in $\Gamma$. However, because a deviation to every mechanism $\gamma^{\prime}$ in $\Gamma$ induces an incentive consistent truth telling continuation equilibrium and a single fixed price (i. e., the expected price $p^{\prime}$ ), an equilibrium $\{\hat{\varphi}, \hat{\pi}\}$, relative to fixed prices, is robust to the possibility of deviating to any mechanism in $\Gamma$, if no seller can gain in every incentive consistent truth telling continuation equilibrium upon deviating to any single fixed price. This is the sufficient condition that is proved in Theorem 1. Because the set of single fixed prices is also one possible set of (constant) mechanisms, the proof of the necessary condition is clear.

There is no a priori reason to think that every equilibrium $\{\hat{\varphi}, \hat{\pi}\}$ of an auxiliary competing mechanism game satisfies the necessary and sufficient condition for robustness in Theorem 1, because an equilibrium is subject to a particular incentive consistent truth telling continuation equilibrium $\hat{\pi}$. Proposition 2 shows that the necessary and sufficient condition is satisfied for an equilibrium of an auxiliary competing mechanism game.

Proposition 2: Consider an equilibrium $\{\hat{\varphi}, \hat{\pi}\}$ of an auxiliary competing mechanism game. Then, for every incentive consistent truth telling continuation equilibrium $\hat{\pi}^{\prime}$, we have

$$
\sup _{p \in[0,1]} \Phi\left(p, \hat{\varphi}^{m-1}, \hat{\pi}^{\prime}\right)=n \hat{p}_{1},
$$


where $\hat{p}_{1}=\hat{\varphi}_{1}(0)$ is the equilibrium price that a seller charges upon only one buyer selecting him. Therefore, an equilibrium $\{\hat{\varphi}, \hat{\pi}\}$ of an auxiliary competing mechanism game is robust to any $\Gamma$ according to Theorem 1.

Proof: See Appendix.

The proof in the Appendix shows that there are indeed multiple incentive consistent truth telling continuation equilibria upon a seller's deviation, given any equilibrium $\{\hat{\varphi}, \hat{\pi}\}$. However, it is shown that in all incentive consistent truth telling continuation equilibria, the supremum of the deviating seller's profit is $n \hat{p}_{1}$, which is the profit that the seller would get if he could sell his products to all buyers at the equilibrium price $\hat{p}_{1}=\hat{\varphi}_{1}(0)$, contingent on only one participating buyer. Therefore, the necessary and sufficient condition for robustness in Theorem 1 is satisfied with equality and with that, an equilibrium $\{\hat{\varphi}, \hat{\pi}\}$ of an auxiliary competing mechanism game is robust.

\section{Equilibrium Characterization}

Because of Propositions 1 and 2, we can assert that the set of robust equilibrium allocations in a competing mechanism game $\Gamma$ is the same as that in auxiliary competing mechanism games. Therefore, we can characterize the set of equilibrium allocations by focusing on mechanisms with the binary report and the worst punishment. This allows us to characterize all equilibrium prices. Let $\left(\hat{p}_{1}, \ldots, \hat{p}_{n}\right)$ denote the vector of prices that a seller charges, contingent on the number of participating buyers in an equilibrium.

Proposition 3: For any given numbers of sellers and buyers, $m$ and $n$, the equilibrium price vector $\left(\hat{p}_{1}, \ldots, \hat{p}_{n}\right)$ is characterized by $(a) \hat{p}_{1} \in\left[0, \bar{p}_{1}\right]$, where

$$
\bar{p}_{1}=\frac{1-\left(1-\frac{1}{m}\right)^{n-1}}{m-\left(1-\frac{1}{m}\right)^{n-1}},
$$

and $(b)$ for any given $\hat{p}_{1} \in\left[0, \bar{p}_{1}\right],\left(\hat{p}_{2}, \ldots, \hat{p}_{n}\right)$ satisfies

$$
n \hat{p}_{1} \leq \sum_{k=1}^{n}\left(\begin{array}{l}
n \\
k
\end{array}\right)\left(\frac{1}{m}\right)^{k}\left(1-\frac{1}{m}\right)^{n-k} k \hat{p}_{k} .
$$

As $m \rightarrow \infty$, given the fixed ratio $b=n / m,\left(\hat{p}_{1}, \ldots, \hat{p}_{n}\right)$ satisfies (i) $\hat{p}_{1} \rightarrow 0$ and (ii) for any $\tau \in\left[0, b\left(1-e^{-b}\right)\right]$, 


$$
\tau \leq \sum_{k=2}^{\infty} \frac{b^{k} e^{-b}}{k !} k \hat{p}_{k}
$$

Proof: First, consider the finite market. For any equilibrium $\{\hat{\varphi}, \hat{\pi}\}$ of an auxiliary competing mechanism game, $\hat{\varphi}$ satisfies

$$
\begin{aligned}
& n \hat{p}_{1}=\sup _{p \in[0,1]} \Phi\left(p, \hat{\varphi}^{m-1}, \hat{\pi}\right) \leq \\
& \Phi\left(\hat{\varphi}, \hat{\varphi}^{m-1}, \hat{\pi}\right)=\sum_{k=1}^{n}\left(\begin{array}{l}
n \\
k
\end{array}\right)\left(\frac{1}{m}\right)^{k}\left(1-\frac{1}{m}\right)^{n-k} k \hat{p}_{k},
\end{aligned}
$$

where the equality is due to eq. [4], which is satisfied for every incentive consistent truth telling continuation equilibrium. Expression [8] is equivalent to the following inequality

$$
n\left(1-\left(\frac{1}{m}\right)\left(1-\frac{1}{m}\right)^{n-1}\right) \hat{p}_{1} \leq \sum_{k=2}^{n}\left(\begin{array}{l}
n \\
k
\end{array}\right)\left(\frac{1}{m}\right)^{k}\left(1-\frac{1}{m}\right)^{n-k} k \hat{p}_{k} .
$$

Because $\hat{p}_{k} \leq 1$ for all $k$, eq. [9] provides the upper bound of $\hat{p}_{1}$. This upper bound is expressed in eq. [5]. For any given $\hat{p}_{1} \in\left[0, \bar{p}_{1}\right]$, any $\left(\hat{p}_{2}, \ldots, \hat{p}_{n}\right)$ satisfying eq. [8] is then supportable in any equilibrium.

Now consider a large market as $m \rightarrow \infty$. In an equilibrium, $\hat{p}_{1} \in\left[0, \bar{p}_{1}\right]$ according to (a) and

$$
\lim _{m \rightarrow \infty} \bar{p}_{1}=\lim _{m \rightarrow \infty} \frac{1-\left(1-\frac{1}{m}\right)^{b m-1}}{m-\left(1-\frac{1}{m}\right)^{b m-1}}=0 .
$$

Because $\bar{p}_{1} \rightarrow 0$ as $m \rightarrow \infty, \hat{p}_{1} \rightarrow 0$.

For any given $\hat{p}_{1} \in\left[0, \bar{p}_{1}\right]$, equilibrium prices for $k \geq 2$ satisfy eq. [6], where the left hand side, $n \hat{p}_{1}=b m \hat{p}_{1}$, is the supremum of the profit that a deviating seller can ensure in any incentive consistent truth telling continuation equilibrium. If $\hat{p}_{1}=0$, then $n \hat{p}_{1}=0$. If $\hat{p}_{1}=\bar{p}_{1}$, the maximum profit for the deviating seller is $b m \bar{p}_{1}$. Note that

$$
\lim _{m \rightarrow \infty} b m \bar{p}_{1}=\lim _{m \rightarrow \infty} b m\left(\frac{1-\left(1-\frac{1}{m}\right)^{b m-1}}{m-\left(1-\frac{1}{m}\right)^{b m-1}}\right)=b\left(1-e^{-b}\right) .
$$

Therefore, for any given $\hat{p}_{1} \in\left[0, \bar{p}_{1}\right]$, the supremum of the profit for the deviating seller is no less than 0 and no greater than $b\left(1-e^{-b}\right)$ as $m \rightarrow \infty$.

Suppose that $\hat{p}_{1}$ is the equilibrium price for $k=1$, which induces the deviating seller's profit $\tau \in\left[0, b\left(1-e^{-b}\right)\right]$. In order to prevent a seller from deviating, the equilibrium expected profit on the right-hand side of eq. [6] must be no less 
than $\tau$. The number of participating buyers, $k$, is a random variable that follows a binomial distribution, where the probability of each buyer visiting a seller is $1 / m$ on the equilibrium path. As $m \rightarrow \infty$, this binomial distribution converges to the Poisson distribution with parameter $b=\frac{n}{m}$. Furthermore, a seller's expected profit from selling to only one buyer, $b\left(1-\frac{1}{m}\right)^{b m-1} \hat{p}_{1}$, approaches zero because $\hat{p}_{1} \rightarrow 0$ as $m \rightarrow \infty$. Therefore, the right-hand side of eq. [6] converges to $\sum_{k=2}^{\infty} \frac{b^{k} e^{-b}}{k !} k \hat{p}_{k}$.

First, consider the equilibrium price vector in the finite market. If a seller raises $\hat{p}_{1}$, his expected profit goes up because it creates a higher profit upon only one buyer's participation. However, it increases the supremum of the deviating seller's profit, which is equal to $n \hat{p}_{1}$ in any incentive consistent truth telling continuation equilibrium according to Proposition 2. This creates a trade-off when sellers set up $\hat{p}_{1}$ and this trade-off imposes the upper bound $\bar{p}_{1}$ as eq. [5], which prevents any seller's deviation. Inequality eq. [6] states that, for any given $\hat{p}_{1} \in\left[0, \bar{p}_{1}\right]$, the admissible values for $\left(\hat{p}_{2}, \ldots, \hat{p}_{n}\right)$ must make a seller's equilibrium profit no less than the profit that he can make upon deviation: for any given $\hat{p}_{1} \in\left[0, \bar{p}_{1}\right]$, each $\hat{p}_{k}$ for $k \geq 2$ can be as high as 1 , but the lowest possible values for $\left(\hat{p}_{2}, \ldots, \hat{p}_{n}\right)$ are tied to the value of $\hat{p}_{1} \cdot{ }^{15}$ If those prices $\left(\hat{p}_{2}, \ldots, \hat{p}_{n}\right)$ are too low, a seller's expected profit is lowered, which makes it profitable for a seller to deviate from $\hat{\varphi}$.

Second, consider the equilibrium price vector in a large market with $m \rightarrow \infty$ given the fixed ratio $b=n / m$. Most importantly, given any fixed ratio $b$, as $m \rightarrow \infty$ (i. e. the numbers of sellers and buyers both increases given a fixed ratio $b$ ), $\hat{p}_{1}$ converges to the competitive price i. e., marginal cost. This is because its upper bound $\bar{p}_{1} \rightarrow 0$ as $m \rightarrow \infty$ for any given $b$. This implies that in a large market, a seller's positive profit can come from selling his product only when multiple buyers select him. Although the upper bound of $\hat{p}_{1}$ converges to zero as $m \rightarrow \infty$, the supremum of the deviating seller's profit, $b m \bar{p}_{1}$, associated with the upper bound $\bar{p}_{1}$ converges to $b\left(1-e^{-b}\right)$, but not to zero. Therefore, the supremum of a deviating seller's profit, denoted by $\tau=b m \hat{p}_{1}$, can be any level in $\left[0, b\left(1-e^{-b}\right)\right]$. This is how to convert eqs [6] to [7] for the large market.

Given the multiplicity of ex-post equilibria, it is interesting to derive the ranges of a seller's expected equilibrium profit and the expected equilibrium price that he charges.

15 For example, when $n=m=2$, the range for the equilibrium price $\hat{p}_{1}$ is $[0,1 / 3]$. If $\hat{p}_{1}=0$, then $\hat{p}_{2}$ can be any value in $[0,1]$. If $\hat{p}_{1}=1 / 3$, then the only possible value for $\hat{p}_{2}$ is 1 . 
Corollary 1: The range of the equilibrium expected price that a seller charges upon selling his product is $\left[0, \bar{p}_{e}\right]$, where

$$
\bar{p}_{e}=\frac{\frac{n}{m}\left(1-\frac{1}{m}\right)^{n-1}}{1-\left(1-\frac{1}{m}\right)^{n}} \bar{p}_{1}+\left(1-\frac{\frac{n}{m}\left(1-\frac{1}{m}\right)^{n-1}}{1-\left(1-\frac{1}{m}\right)^{n}}\right)
$$

and the range of a seller's equilibrium expected profit upon selling his product is $\left[0, \bar{v}_{e}\right]$, where

$$
\bar{v}_{e}=\frac{\frac{n}{m}}{1-\left(1-\frac{1}{m}\right)^{n}}\left(1-\left(1-\frac{1}{m}\right)^{n-1}\left(1-\bar{p}_{1}\right)\right) .
$$

Given the fixed ratio $b=n / m, \lim _{m \rightarrow \infty} \bar{p}_{e}=1-\frac{b e^{-b}}{1-e^{-b}}$ and $\lim _{m \rightarrow \infty} \bar{v}_{e}=b$.

Proof: The lowest expected price that a seller charges upon selling his product is zero because it is possible to have $\hat{p}_{k}=0$ for all $k$ in an equilibrium according to conditions 1 and 2 in Proposition 3. The highest expected price can be derived when $\hat{p}_{1}=\bar{p}_{1}$ and $\hat{p}_{k}=1$ for all $k \geq 2$. Therefore, the range of the expected equilibrium prices that a seller charges upon selling his product is $\left[0, \bar{p}_{e}\right]$, where

$$
\bar{p}_{e}=\frac{\operatorname{Pr}(k=1)}{\operatorname{Pr}(k \geq 1)} \times \bar{p}_{1}+\frac{\operatorname{Pr}(k \geq 2)}{\operatorname{Pr}(k \geq 1)} \times 1 .
$$

Because each buyer chooses each seller with equal probability in equilibrium, i. e., $\hat{\pi}\left(\hat{\varphi}^{m}\right)=1 / m$, we have

$$
\begin{aligned}
& \operatorname{Pr}(k \geq 1)=1-\left(1-\frac{1}{m}\right)^{n}, \\
& \operatorname{Pr}(k=1)=\frac{n}{m}\left(1-\frac{1}{m}\right)^{n-1}, \\
& \operatorname{Pr}(k \geq 2)=1-\frac{n}{m}\left(1-\frac{1}{m}\right)^{n-1}-\left(1-\frac{1}{m}\right)^{n} .
\end{aligned}
$$

Therefore, the upper bound of the expected equilibrium price $\bar{p}_{e}$ that a seller charges upon selling his product is expressed as eq. [10].

The lowest expected profit for a seller upon selling his product is zero because it is possible to have $\hat{p}_{k}=0$ for all $k$ in an equilibrium. The seller's expected equilibrium profit upon selling his product is highest when $\hat{p}_{1}=\bar{p}_{1}$ and 
$\hat{p}_{k}=1$ for all $k \geq 2$. Therefore, the seller's highest equilibrium expected profit upon selling his product is

$$
\bar{v}_{e}=\sum_{s=1}^{n} \frac{\operatorname{Pr}(k=s)}{\operatorname{Pr}(k \geq 1)} s-\frac{\operatorname{Pr}(k=1)}{\operatorname{Pr}(k \geq 1)} \times\left(1-\bar{p}_{1}\right) .
$$

Because of eqs [12], [13], and

$$
\operatorname{Pr}(k=s)=\left(\begin{array}{l}
n \\
s
\end{array}\right)\left(\frac{1}{m}\right)^{s}\left(1-\frac{1}{m}\right)^{n-s},
$$

$\bar{v}_{e}$ is expressed as eq. [11].

As $m \rightarrow \infty$, the number of buyers who buy the product from a seller follows a Poisson distribution with parameter $b$. Therefore, we have $\operatorname{Pr}(k \geq 1) \rightarrow 1-e^{-b}$, $\operatorname{Pr}(k=1) \rightarrow b e^{-b}$, and $\operatorname{Pr}(k \geq 2) \rightarrow 1-b e^{-b}-e^{-b}$. Because $\bar{p}_{1} \rightarrow 0$ as $m \rightarrow \infty$, we have

$$
\lim _{m \rightarrow \infty} \bar{p}_{e}=\lim _{m \rightarrow \infty} \frac{\operatorname{Pr}(k \geq 2)}{\operatorname{Pr}(k \geq 1)}=1-\frac{b e^{-b}}{1-e^{-b}},
$$

which is the probability of selling the product to multiple buyers conditional on selling the product to at least one buyer. As $m \rightarrow \infty$, we have $\bar{p}_{1} \rightarrow 0$ and

$$
\operatorname{Pr}(k=s)=\left(\begin{array}{c}
n \\
s
\end{array}\right)\left(\frac{1}{m}\right)^{s}\left(1-\frac{1}{m}\right)^{n-s} \rightarrow \frac{b^{s} e^{-b}}{s !} .
$$

Therefore, we have $\lim _{m \rightarrow \infty} \bar{v}_{e}=b$.

The lower bounds of the expected price and profit are based on competitive equilibrium prices, i.e., $\hat{p}_{k}=0$ for all $k$. The upper bounds are based on the highest possible equilibrium prices, i. e., $\hat{p}_{1}=\bar{p}_{1}$ and $\hat{p}_{k}=1$ for all $k \geq 2$. As the ratio of buyers to sellers $b=n / m$ increases, the fraction of sellers chosen by multiple buyers increases (and the fraction of sellers chosen by only one buyer decreases) because the probability $\operatorname{Pr}(k \geq 2 \mid k \geq 1)$ with which multiple buyers select a seller conditional on at least one buyer selecting him increases in $b$. As $b \rightarrow \infty$, the upper bound of the expected price is one and the upper bound of the expected profit increases indefinitely. On the other hand, as $b \rightarrow 0$, the equilibrium outcome converges to the conventional competitive equilibrium outcome where trading occurs at the competitive price because the upper bounds of both the expected price and expected profit converge to zero as well.

In a large market with any given positive ratio $b$, a seller sells his products at the competitive price $\hat{p}_{1}=0$ when only one buyer selects him, but he can sell at a collusive price (i. e., a price above the competitive level) when two or more 
buyers selects him. ${ }^{16}$ For any given $b$, the probability of only one buyer selecting a seller, $\operatorname{Pr}(k=1)$, is $b e^{-b}$ but the probability of two or more buyers selecting a seller, $\operatorname{Pr}(k \geq 2)$, is $1-b e^{-b}-e^{-b}$. Therefore, in a large market, a seller cannot always charge a collusive price, only with the probability $1-b e^{-b}-e^{-b}$. This is caused by (i) the mis-coordination among buyers that makes it possible that a seller may some times have only one buyer and (ii) the fact that in a large market, a seller charges the competitive price when only one buyer selects him.

\section{Discussion}

This paper shows a notion of an equilibrium that is tractable in terms of market information revelation in a directed search market, where the number of buyers selecting a particular seller is stochastically determined in equilibrium. An auxiliary competing mechanism game with mechanisms employing the binary report and the worst punishment characterizes the set of all possible allocations that can be supported in a robust equilibrium of a competing mechanism game with any arbitrary set of mechanisms. In addition, it provides comparative statics regarding the range of equilibrium prices and profits. Even in a large market, collusive prices can be supported in an equilibrium and the probability that sellers can sell their products at collusive prices depends on the ratio of buyers to sellers.

The analysis of equilibrium and its robustness in our paper is based on the truth-telling continuation equilibrium, where buyers reveal true market information in order to find out the set of equilibrium allocations that can be supported when non-deviating sellers change their terms of trade in response to a competing seller's deviation. However, it is also a continuation equilibrium that buyers continue to report "no deviation by any sellers $(t=0)$ " to every non-deviating seller even when a seller deviates. In this case, non-deviating sellers keep their equilibrium terms of trade regardless of a competing seller's deviation. If a nondeviating seller's terms of trade were to be independent of buyers' messages on the market information, it would not matter whether or not buyers report true market information. Indeed, the type of competing mechanism games where buyers are not allowed to report their market information (report only their payoff types if types are not publicly observable (e.g., competing auctions)),

16 One may not need to literally interpret the number of buyers selecting a seller. An alternative interpretation would be that a seller's mechanism charges the competitive price if the realized demand for his product is low, but he can charge a collusive price (or a price higher than the competitive level) if the realized demand is high. 
induces an equilibrium independent of buyers' revelation of market information. Peters (1997) and Han (2007, 2015) study this type of competing mechanism games. ${ }^{17}$ In this type of competing mechanism games, non-deviating sellers' terms of trade are fixed regardless of a competing seller's deviation.

The other type of competing mechanism games in the literature (Yamashita 2010; Peters and Troncoso-Valverde 2013) allows buyers to reveal their market information. This leads to collusive equilibrium outcomes, when buyers truthfully report their market information to non-deviating sellers on the equilibrium path and also off the path following a seller's deviation. Although this second type of games generates more equilibrium outcomes, the equilibrium mechanisms generally admit multiple continuation equilibria in terms of market information revelation and the mechanism with the binary report and the worst punishment proposed in our paper is not an exception. Because a seller takes messages reported by the majority of buyers, a false market information can be incorrectly viewed as the true market information if all participating buyers send it.

In the game theoretic analysis, it is necessary to restrict the set of selling mechanisms that sellers can offer as their strategy space. Therefore, in both types of games, we cannot take for granted the equilibrium robustness to the possibility of a seller's deviation to arbitrary mechanism that is not allowed in the game. The robustness analysis in the second type of the games is based on the truth-telling continuation equilibrium about the market information on and off the path. This is also the approach that our paper takes in the robustness analysis.

Clearly, the robustness of an equilibrium in the first type of competing mechanism game is stronger because the equilibrium terms of trade are free from whether or not buyers report their true market information. This is also the reason why the set of equilibrium allocations in this type of games is typically smaller: for example, as the number of traders, given a fixed ratio of buyers to sellers, increases, the competing auction game produces the robust equilibrium where a seller's reserve price is equal to his cost (Peters 1997).

By adopting a selling mechanism that allows buyers to reveal their market information, sellers can support many more, often collusive, equilibrium

17 In Peters (1997), sellers are restricted to offer only auctions so that buyers are only allowed to submit their bids, but not their market information. Han (2015) shows that the notion of equilibrium adopted in Peters (1997) includes the robustness to the possibility of a seller's deviation to any arbitrary mechanism. Han (2007) studies the robust equilibrium in the game where principals offer a single incentive contract (e. g., nonlinear price schedule) to each agent, with no private information on agents' types. Therefore, a principal does not make his contract offer contingent on buyers' market information. 
outcomes, even when the number of traders is large given a fixed ratio of buyers to sellers. Those equilibrium outcomes are also robust to the possibility of a seller's deviation to any arbitrary mechanism, but subject to buyers' truthful revelation of market information. Given the possible non-truthful continuation equilibrium, the degree and scope of sellers' collusion does seem to depend on how to implement a selling mechanism in a way that buyers' messaging behavior can naturally reflect what they know about what is happening in the market (e. g. click stream pricing). Further research is required to have a better understanding of designing and implementation of such mechanisms.

Acknowledgements: For their comment, I would like to thank an anonymous referee, the editor, Maxim Ivanov, and Gábor Virág. I would also like to thank Joe Lesica for his superb research assistance. I thankfully acknowledge the financial support from SSHRC of Canada. All errors are mine alone.

\section{Appendix}

Proof of Proposition 1: Consider an equilibrium $\{\gamma, c, \pi\}$ of a competing mechanism game with $\Gamma$. Suppose that every seller offers a mechanism $\hat{\varphi}$ satisfying properties (i)-(iv) in the proof of Lemma 1, with

$$
\left[p_{1}, \ldots, p_{n}\right]=\left[p_{1}^{\gamma}\left(\gamma^{m-1}, c\right), \ldots, p_{n}^{\gamma}\left(\gamma^{m-1}, c\right)\right]
$$

as the price vector that specifies prices that the seller charges given the participating buyers' truthful consistent reporting when there are no deviations by other sellers (i.e., $t=0$ ). Let each buyer choose each seller with probability $\hat{\pi}\left(\hat{\varphi}^{m}\right)=\pi\left(\gamma^{m}\right)=1 / m$ by reporting 0 . Then, each seller's expected price that a buyer faces upon participation is

$$
\begin{aligned}
\mathbb{E}\left[\hat{\varphi}_{k}\left(0^{k}\right)\right] & =\sum_{k=1}^{n}\left(\begin{array}{c}
n-1 \\
k-1
\end{array}\right) \hat{\pi}\left(\hat{\varphi}^{m}\right)^{k-1}\left(1-\hat{\pi}\left(\hat{\varphi}^{m}\right)\right)^{n-k} \hat{\varphi}_{k}\left(0^{k}\right) \\
& =\sum_{k=1}^{n}\left(\begin{array}{c}
n-1 \\
k-1
\end{array}\right) \pi\left(\gamma^{m}\right)^{k-1}\left(1-\pi\left(\gamma^{m}\right)\right)^{n-k} p_{k}^{y}\left(\gamma^{m-1}, c\right) \\
& =\mathbb{E}\left[p_{k}^{\gamma}\left(\gamma^{m-1}, c\right)\right]
\end{aligned}
$$

because $\hat{\pi}\left(\hat{\varphi}^{m}\right)=\pi\left(\gamma^{m}\right)$ and $\hat{\varphi}_{k}\left(0^{k}\right)=p_{k}^{\gamma}\left(\gamma^{m-1}, c\right)$ for all $k$. Therefore, it is an incentive consistent truth telling continuation equilibrium that each buyer chooses each seller with the probability $\hat{\pi}\left(\hat{\varphi}^{m}\right)$ and reports $t=0$ upon participation. Because each seller's expected price is preserved, the buyer's expected payoff is preserved: 


$$
1-\mathbb{E}\left[\hat{\varphi}_{k}\left(0^{k}\right)\right]=1-\mathbb{E}\left[p_{k}^{y}\left(\gamma^{m-1}, c\right)\right] .
$$

Given truthful continuation equilibrium, each seller's expected payoff satisfies

$$
\Phi\left(\hat{\varphi}, \hat{\varphi}^{m-1}, \hat{\pi}\right)=\Phi\left(\gamma, \gamma^{m-1}, c, \pi\right)
$$

because $\hat{\pi}\left(\hat{\varphi}^{m}\right)=\pi\left(\gamma^{m}\right)$ and $\hat{\varphi}_{k}\left(0^{k}\right)=p_{k}^{\gamma}\left(\gamma^{m-1}, c\right)$ for all $k$.

Now suppose that one seller deviates to $p$. Pick a constant mechanism $\gamma^{\prime}$ that always assigns $p$ regardless of the participating buyers' reports. In the original competing mechanism game $\Gamma$, the deviating seller's price is always $p$, but the expected price that a buyer faces upon participating in each non-deviating seller's mechanism $\hat{\varphi}$ is

$$
\begin{aligned}
& \mathbb{E}\left[p_{k}^{\gamma}\left(\gamma^{\prime}, \gamma^{m-2}, c\right)\right]= \\
& \sum_{k=1}^{n}\left(\begin{array}{c}
n-1 \\
k-1
\end{array}\right)\left(\frac{1-\pi\left(\gamma^{\prime}, \gamma^{m-1}\right)}{m-1}\right)^{k-1}\left(1-\frac{1-\pi\left(\gamma^{\prime}, \gamma^{m-1}\right)}{m-1}\right)^{n-k} p_{k}^{\gamma}\left(\gamma^{\prime}, \gamma^{m-2}, c\right) .
\end{aligned}
$$

In the auxiliary competing mechanism game, suppose that a buyer chooses the deviating seller with probability $\hat{\pi}\left(p, \hat{\varphi}^{m-1}\right)=\pi\left(\gamma^{\prime}, \gamma^{m-1}\right)$ upon his deviation to $p$ and each non-deviating seller with equal probability. The expected price that a buyer faces upon selecting a non-deviating seller is

$$
\begin{aligned}
& \mathbb{E}\left[\hat{\varphi}_{k}\left(1^{k}\right)\right] \\
& =\sum_{k=1}^{n}\left(\begin{array}{l}
n-1 \\
k-1
\end{array}\right)\left(\frac{1-\hat{\pi}\left(p, \hat{\varphi}^{m-1}\right)}{m-1}\right)^{k-1}\left(1-\frac{1-\hat{\pi}\left(p, \hat{\varphi}^{m-1}\right)}{m-1}\right)^{n-k} \hat{\varphi}_{k}\left(1^{k}\right)
\end{aligned}
$$

Note that $\hat{\varphi}_{1}(1)=p_{1}^{\gamma}\left(\gamma^{\prime}, \gamma^{m-2}, c\right)$ because $p_{1}^{\gamma}\left(\gamma^{\prime}, \gamma^{m-2}, c\right)=p_{1}^{\gamma}\left(\gamma^{\prime \prime}, \gamma^{m-2}, c\right)$ for all $\gamma^{\prime}, \gamma^{\prime \prime} \in \Gamma$ due to a property of an equilibrium $\{\gamma, c, \pi\}$. (See item 3 of Definition 1.) Furthermore, $\hat{\varphi}_{k}\left(1^{k}\right)=0 \leq p_{k}^{\gamma}\left(\gamma^{\prime}, \gamma^{m-2}, c\right)$ for all $k \geq 2$. Therefore, given the initial setup of $\hat{\pi}\left(p, \hat{\varphi}^{m-1}\right)=\pi\left(\gamma^{\prime}, \gamma^{m-1}\right)$, from eqs [16] and [17], we can infer that

$$
\mathbb{E}\left[\hat{\varphi}_{k}\left(1^{k}\right)\right] \leq \mathbb{E}\left[p_{1}^{\gamma}\left(\gamma^{\prime}, \gamma^{m-2}, c\right)\right] .
$$

Equivalently, the buyer's expected payoff upon selecting a non-deviating seller who offers $\hat{\varphi}$ is

$$
1-\mathbb{E}\left[\hat{\varphi}_{k}\left(1^{k}\right)\right] \geq 1-\mathbb{E}\left[p_{1}^{y}\left(\gamma^{\prime}, \gamma^{m-2}, c\right)\right] .
$$

The buyer's expected payoff, $1-\mathbb{E}\left[\hat{\varphi}_{k}\left(1^{k}\right)\right]$, is decreasing in $\hat{\pi}\left(p, \hat{\varphi}^{m-1}\right)$ because a non-deviating seller's expected price $\mathbb{E}\left[\hat{\varphi}_{k}\left(1^{k}\right)\right]$ is increasing in $\hat{\pi}\left(p, \hat{\varphi}^{m-1}\right)$, as shown on the last line in eq. [17]. Because the buyer's expected payoff upon selecting the deviating seller is the same whether he offers $p$ in the auxiliary 
competing mechanism game or he offers $\gamma^{\prime}$ in the original competing mechanism game, eq. [19] implies that there exists an incentive consistent truth telling continuation equilibrium in which we have

$$
\hat{\pi}\left(p, \hat{\varphi}^{m-1}\right) \leq \pi\left(\gamma^{\prime}, \gamma^{m-1}\right)
$$

upon a seller's deviation to $p$. Because eq. [20] is satisfied and $\gamma^{\prime}$ is a constant mechanism that always charges $p$, the deviating seller's expected payoff satisfies

$$
\Phi\left(p, \hat{\varphi}^{m-1}, \hat{\pi}\right)=n \hat{\pi}\left(p, \hat{\varphi}^{m-1}\right) p \leq n \pi\left(\gamma^{\prime}, \gamma^{m-1}\right) p=\Phi\left(\gamma^{\prime}, \gamma^{m-1}, c, \pi\right) .
$$

Because $\Phi\left(\gamma, \gamma^{m-1}, c, \pi\right) \geq \Phi\left(\gamma^{\prime}, \gamma^{m-1}, c, \pi\right)$ for all $p$, eqs [15] and [21] imply that, for all $p$,

$$
\Phi\left(\hat{\varphi}, \hat{\varphi}^{m-1}, \hat{\pi}\right) \geq \Phi\left(p, \hat{\varphi}^{m-1}, \hat{\pi}\right)
$$

and hence, no seller has an incentive to deviate to a single fixed price in the auxiliary competing mechanism game. This completes the proof.

Proof of Theorem 1: Consider an equilibrium $\{\hat{\varphi}, \hat{\pi}\}$ of an auxiliary competing mechanism game where each seller either offers a mechanism $\hat{\varphi}$ with the binary report and the worst punishment or deviates to a single fixed price. Suppose that a seller deviates to an arbitrary mechanism in $\Gamma$ instead of deviating to a single fixed price. Given Lemma 1, we fix the buyer's truth telling $t=1$ to each nondeviating seller upon participation. Let buyers play an incentive consistent truth telling continuation equilibrium in which each buyer sends a message to the deviating seller according to $c\left(\gamma^{\prime}, \hat{\varphi}^{m-1}\right) \in \Delta(C)$ upon selecting him and selects the deviating seller with probability $\left.\pi\left(\gamma^{\prime}, \hat{\varphi}^{m-1}\right)\right\}$ and each non-deviating seller with equal probability. The deviating seller's expected payoff upon deviating to $\gamma^{\prime}$ is $\Phi\left(\gamma^{\prime}, \hat{\varphi}^{m-1}, c, \pi\right)=n \pi\left(\gamma^{\prime}, \hat{\varphi}^{m-1}\right) \mathbb{E}\left[p_{k}^{\gamma^{\prime}}\left(\hat{\varphi}^{m-1} ; c\right)\right]$, where $\mathbb{E}\left[p_{k}^{\gamma^{\prime}}\left(\hat{\varphi}^{m-1} ; c\right)\right]$ is the expected price upon selecting the deviating seller:

$$
\begin{aligned}
& E\left[p_{k}^{\gamma^{\prime}}\left(\hat{\varphi}^{m-1} ; c\right)\right]= \\
& \sum_{k=1}^{n}\left(\begin{array}{c}
n-1 \\
k-1
\end{array}\right) \pi\left(\gamma^{\prime}, \hat{\varphi}^{m-1}\right)^{k-1}\left(1-\pi\left(\gamma^{\prime}, \hat{\varphi}^{m-1}\right)\right)^{n-k} p_{k}^{\gamma^{\prime}}\left(\hat{\varphi}^{m-1} ; c\right) .
\end{aligned}
$$

Suppose that the deviating seller offers $p^{\prime}=\mathbb{E}\left[p_{k}^{y^{\prime}}\left(\hat{\varphi}^{m-1} ; c\right)\right]$ instead of $\gamma^{\prime}$. Then it is also an incentive consistent truth telling continuation equilibrium that each buyer chooses the deviating seller with probability $\hat{\pi}^{\prime}\left(p^{\prime}, \hat{\varphi}^{m-1}\right)=\pi\left(\gamma^{\prime}, \hat{\varphi}^{m-1}\right)$ and each non-deviating seller with equal probability. In this incentive consistent truth telling continuation equilibrium, the deviating seller's expected payoff satisfies 


$$
\begin{aligned}
& \Phi\left(p^{\prime}, \hat{\varphi}^{m-1}, \hat{\pi}^{\prime}\right)=n \hat{\pi}^{\prime}\left(p^{\prime}, \hat{\varphi}^{m-1}\right) p^{\prime}= \\
& n \pi\left(\gamma^{\prime}, \hat{\varphi}^{m-1}\right) \mathbb{E}\left[p_{k}^{\gamma^{\prime}}\left(\hat{\varphi}^{m-1} ; c\right)\right]=\Phi\left(\gamma^{\prime}, \hat{\varphi}^{m-1}, c, \pi\right)
\end{aligned}
$$

Because $\Phi\left(p^{\prime}, \hat{\varphi}^{m-1}, \hat{\pi}^{\prime}\right)=\Phi\left(\gamma^{\prime}, \hat{\varphi}^{m-1}, c, \pi\right)$, eq. [3] ensures

$$
\Phi\left(\hat{\varphi}, \hat{\varphi}^{m-1}, \hat{\pi}\right) \geq \Phi\left(\gamma^{\prime}, \hat{\varphi}^{m-1}, c, \pi\right) .
$$

Therefore, it is not profitable for a seller to deviate to any mechanism $\gamma^{\prime}$. This proves the "if" part. Because the set of single fixed prices is also one possible set of (constant) mechanisms, the proof of "only if" part is clear.

Proof of Proposition 2: Consider an equilibrium $\{\hat{\varphi}, \hat{\pi}\}$ where each seller either offers a mechanism $\hat{\varphi}$ with the binary report and the worst punishment or deviates to a single fixed price. For all $k$, let $\hat{p}_{k}=\hat{\varphi}_{k}\left(0^{k}\right)$ be the seller's equilibrium price conditional on $k$ participating buyers when no seller deviates and each participating buyer reports $t=0$. We fix a buyer's truth-telling to each nondeviating seller.

When no seller deviates from $\hat{\varphi}$, a buyer selects each seller with equal probability $\hat{\pi}\left(\hat{\varphi}^{m}\right)=1 / m$. Subsequently, each seller's expected payoff is

$$
\Phi\left(\hat{\varphi}, \hat{\varphi}^{m-1}, \hat{\pi}\right)=\sum_{k=1}^{n}\left(\begin{array}{l}
n \\
k
\end{array}\right)\left(\frac{1}{m}\right)^{k}\left(1-\frac{1}{m}\right)^{n-k} k \hat{p}_{k} .
$$

In an incentive consistent truth-telling continuation equilibrium, upon a seller's deviation to a fixed price $p$, a buyer selects the deviating seller with probability $\hat{\pi}^{\prime}\left(p, \hat{\varphi}^{m-1}\right)$ and each non-deviating seller with equal probability $\frac{1-\hat{\pi}^{\prime}\left(p, \hat{\varphi}^{m-1}\right)}{m-1}$. Because the non-deviating seller lowers his price down to zero upon all multiple participating buyers' truthful reports $t=1$, the buyer's expected payoff associated with choosing the non-deviating seller is

$$
1-\left(1-\frac{1-\hat{\pi}^{\prime}\left(p, \hat{\varphi}^{m-1}\right)}{m-1}\right)^{n-1} \hat{p}_{1} .
$$

By choosing the deviating seller, the buyer's expected payoff is $1-p$. If $\hat{\pi}^{\prime}=\hat{\pi}$, then buyers play the original incentive consistent truth-telling continuation equilibrium in $\{\hat{\varphi}, \hat{\pi}\}$. If not, buyers play an alternative incentive consistent truth-telling continuation equilibrium upon a seller's deviation.

By comparing the buyer's expected payoffs, $1-\left(1-\frac{1-\hat{\pi}^{\prime}\left(p, \hat{\varphi}^{m-1}\right)}{m-1}\right)^{n-1} \hat{p}_{1}$ and $1-p$, we can characterize all possible incentive consistent truth-telling continuation equilibria upon a seller's deviation to $p$ below. 


$$
\begin{aligned}
& \hat{\pi}^{\prime}\left(p, \hat{\varphi}^{m-1}\right)= \\
& \left\{\begin{array}{cc}
1 & \text { if } p \leq\left(1-\frac{1}{m-1}\right)^{n-1} \hat{p}_{1} \\
1-(m-1)\left(\begin{array}{c}
\left.1-\left(\frac{p}{\hat{p}_{1}}\right)^{\frac{1}{n-1}}\right) \text { or 1 } \\
1 \text { or } 0
\end{array}\right. & \text { if }\left(1-\frac{1}{m-1}\right)^{n-1} \hat{p}_{1}<p<\hat{p}_{1} \\
0 & \text { if } \hat{p}_{1}=p \\
\text { otherwise(i.e., } \left.\hat{p}_{1}<p\right)
\end{array}\right.
\end{aligned}
$$

When each buyer selects the deviating seller with probability $\hat{\pi}^{\prime}\left(p, \hat{\varphi}^{m-1}\right)$ upon his deviation to $p$, the deviating seller's expected payoff is

$$
\Phi\left(p, \hat{\varphi}^{m-1}, \hat{\pi}^{\prime}\right)=n \hat{\pi}^{\prime}\left(p, \hat{\varphi}^{m-1}\right) p .
$$

Let us consider the supremum of the deviating seller's payoff upon deviation.

(Case 1) $\left(1-\frac{1}{m-1}\right)^{n-1} \hat{p}_{1} \geq p$. There exists a unique incentive consistent truthtelling continuation equilibrium in which every buyer buys the good from the deviating seller with probability one. In this case, the deviating seller's expected payoff becomes $\Phi\left(p, \hat{\varphi}^{m-1}, \hat{\pi}^{\prime}\right)=n p$, which is monotonically increasing and converges to $n\left(1-\frac{1}{m-1}\right)^{n-1} \hat{p}_{1}$ as $p$ approaches $\left(1-\frac{1}{m-1}\right)^{n-1} \hat{p}_{1}$. Therefore, we have that

$$
\sup _{p} \Phi\left(p, \hat{\varphi}^{m-1}, \hat{\pi}^{\prime}\right)=n\left(1-\frac{1}{m-1}\right)^{n-1} \hat{p}_{1} \text {, with the unique } \hat{\pi}^{\prime}\left(p, \hat{\varphi}^{m-1}\right) .
$$

(Case 2) $\left(1-\frac{1}{m-1}\right)^{n-1} \hat{p}_{1}<p<\hat{p}_{1}$. We have two incentive consistent truth-telling continuation equilibria: one mixed-strategy continuation equilibrium and one pure-strategy continuation equilibrium. Whether $\hat{\pi}^{\prime}\left(p, \hat{\varphi}^{m-1}\right)$ equals $1-(m-1)\left(1-\left(\frac{p}{\hat{p}_{1}}\right)^{\frac{1}{n-1}}\right)$ or 1 , eq. [22] is monotonically increasing and converges to $n \hat{p}_{1}$ as $p$ approaches $\hat{p}_{1}$. Therefore, regardless of the incentive consistent truth-telling continuation equilibrium that buyers play, the supremum of the deviating seller's payoff is

$$
\sup _{p} \Phi\left(p, \hat{\varphi}^{m-1}, \hat{\pi}^{\prime}\right)=n \hat{p}_{1} \text { with any } \hat{\pi}^{\prime}\left(p, \hat{\varphi}^{m-1}\right) .
$$

(Case 3) $p=\hat{p}_{1}$. If $\hat{\pi}^{\prime}\left(p, \hat{\varphi}^{m-1}\right)=0$, then the deviating seller has zero profit. If $\hat{\pi}^{\prime}\left(p, \hat{\varphi}^{m-1}\right)=1$, then the deviating seller's payoff is $n \hat{p}_{1}$. Therefore, the supremum of the deviating seller's payoff is

$$
\sup _{p} \Phi\left(p, \hat{\varphi}^{m-1}, \hat{\pi}^{\prime}\right)=n \hat{p}_{1} \text { with } \hat{\pi}^{\prime}\left(p, \hat{\varphi}^{m-1}\right)=1 .
$$


(Case 4) $p>\hat{p}_{1}$. In this case, the deviating seller's expected profit is zero because $\hat{\pi}\left(p, \hat{\varphi}^{m-1}\right)=0$. That is,

$$
\sup _{p} \Phi\left(p, \hat{\varphi}^{m-1}, \hat{\pi}^{\prime}\right)=0 \text { with the unique } \hat{\pi}\left(p, \hat{\varphi}^{m-1}\right) .
$$

If a seller deviates to a single fixed price $p$ that belongs to Case 2 , then the supremum of the deviating seller's payoff is always, regardless of the incentive consistent truth-telling continuation equilibrium that buyers play. Furthermore, eq. [23], [25], and [26] show that the deviating seller's expected profit does not exceed $n \hat{p}_{1}$, regardless of the truth-telling continuation equilibrium that results upon a seller's deviation to a single fixed price that belongs to Case 1, Case 3, or Case 4. Therefore, we can conclude that the supremum of the deviating seller's payoff in every incentive consistent truth-telling continuation equilibrium is $n \hat{p}_{1}$; specifically, for every incentive consistent truth-telling continuation equilibrium $\hat{\pi}^{\prime}$,

$$
\sup _{p \in[0,1]} \Phi\left(p, \hat{\varphi}^{m-1}, \hat{\pi}^{\prime}\right)=n \hat{p}_{1} \text {. }
$$

Thus, the necessary and sufficient condition [3] in Theorem 1 is satisfied with equality and hence, every equilibrium $\{\hat{\varphi}, \hat{\pi}\}$ of an auxiliary competing mechanism game is robust to any $\Gamma$.

\section{References}

Burdett, K., S. Shi, and R. Wright. 2001. "Pricing and Matching with Frictions.” Journal of Political Economy 109 (5):1060-85.

Epstein, L., and M. Peters. 1999. "A Revelation Principle for Competing Mechanisms." Journal of Economic Theory 88 (1):119-60.

McAfee, P. 1993. “Mechanism Design by Competing Sellers.” Econometrica 61 (6):1281-312.

Myerson, R. 1997. Game Theory: Analysis of Conflict. Cambridge, Massachusetts, USA: Harvard University Press.

Han, S. 2007. "Strongly Robust Equilibrium and Competing-Mechanism Games." Journal of Economic Theory 137 (1):610-26.

Han, S. 2015. "Robust Competitive Auctions." Economics Letters 136:207-10.

Peters, M. 1991. "Ex Ante Price Offers in Matching Games Non-Steady States." Econometrica 59 (5):1425-54.

Peters, M. 1997. “A Competitive Distribution of Auctions.” Review of Economic Studies 64 (1):97-123.

Peters, M. 2001. “Common Agency and the Revelation Principle." Econometrica 69 (5):1349-72. Peters, M. 2014. "Competing Mechanisms." Canadian Journal of Economics 47 (2):373-97. Peters, M., and C. Troncoso-Valverde. 2013. "A Folk Theorem for Competing Mechanisms." Journal of Economic Theory 148 (3):953-73.

Yamashita, T. 2010. "Mechanism Games with Multiple Principals and Three or More Agents." Econometrica 78 (2):791-801. 